\title{
EPMA Characterisation of Quartz and Quartz-Cement from a Triassic Sandstone
}

\author{
C.M. MacRae ${ }^{1}$, A. Torpy ${ }^{1}$, C. Delle Piane ${ }^{2}$ and N.C. Wilson ${ }^{1}$ \\ 1. CSIRO Mineral Resources, Microbeam Laboratory, Clayton South, Australia. \\ 2. CSIRO Energy, 26 Dick Perry Ave, Kensington, Western Australia.
}

The Southern Perth Basin of Western Australia has been proposed as a carbon capture and storage region for commercial quantities of $\mathrm{CO} 2$ in a deep saline aquifer hosted by the Triassic fluvial sandstone of the Lesueur Formation. As part of the site characterization four wells were drilled to confirm the stratigraphy of the area and retrieve core material for laboratory analysis. Current depth of the samples analysed here is approximately $1.5 \mathrm{~km}$ below surface although the widespread abundance of quartz overgrowths cement and the palaeo-temperatures estimated from fluid inclusion analysis suggest that maximum burial depth during the past geological history was at least $3 \mathrm{~km}$. Quantitative cathodoluminescence and trace analysis has been used to establish the magnitude and relative timing of diagenetic processes affecting the Lesueur Sandstone and their chemical fingerprint at the microscopic scale. Key to the diagenetic and reservoir properties is understanding the dissolution of feldspar resulting in the precipitation of kaolinite and quartz cements which are common diagenetic reactions that can significantly affect reservoir quality in sandstones containing detrital feldspars. The prosed mechanism being:

$\mathrm{K}$-feldspar $+\mathrm{H}_{2} \mathrm{O} \rightarrow$ kaolinite + quartz

Microstructural analysis indicated that quartz-cement is the most important pore reducing diagenetic phase in the sandstone deposit $[1,2]$. Key to understanding the evolution of the quartz-cement has been the use of cathodoluminescence mapping and x-ray microanalysis to determine the source of the silica in the brine that has precipitated the quartz-cement. Analysing quartz-cement offers challenges in microanalysis due to beam induced local heating leading to damage in the crystalline structure. This has led us to develop liquid nitrogen cathodoluminescence mapping and analysis. We have introduced a liquid nitrogen (LN) cold stage into a FEG-EPMA together with hyperspectral CL and x-ray analysis which has enabled us to extract sub-micron images and avoiding beam induced damage in both the detrital quartz and quartzcement [3, 4]. At LN temperatures we have observed increases in CL emission intensity in both detrital and diagenetic quartz, Fig. 1, enabling lower beam currents to be used for mapping. Microanalysis of the detrital quartz and quartz-cement in the samples, has revealed a reverse correlation between the $1.945 \mathrm{eV}$ emission centre and $\mathrm{Al}$ incorporation and different rates of incorporation appear between detrital and diagenetic quartz, Fig 2. The $\mathrm{Ti}^{4+}$ emission centre in quartz, $2.8 \mathrm{eV}$, was also examined and point analyse compared with the fitted intensity showed the normal response for quartz. Titanium incorporation in quartz grains was observed and a $\mathrm{R}^{2}$ valve of 0.8641 indicates a significant degree of correlation. No detectable correlation was observed between with the $2.8 \mathrm{eV} \mathrm{Ti}{ }^{4+}$ peak and titanium analyses in the quartzcement [5].

\section{References:}

[1] Olierook et al, Marine and Petroleum Geology 50 (2014), p. 83.

[2] Timms et al, Marine and Petroleum Geology 60 (2015), p. 54.

[3] MacRae et al, AMAS 2017 - The 14th Biennial AMAS Symposium, (2017) p. 76.

[4] MacRae et al, Mineralogy and Petrology 107(3) (2013), p. 429. 
[5] Vasyukova et al, American Mineralogist 98 (2013), p. 98.
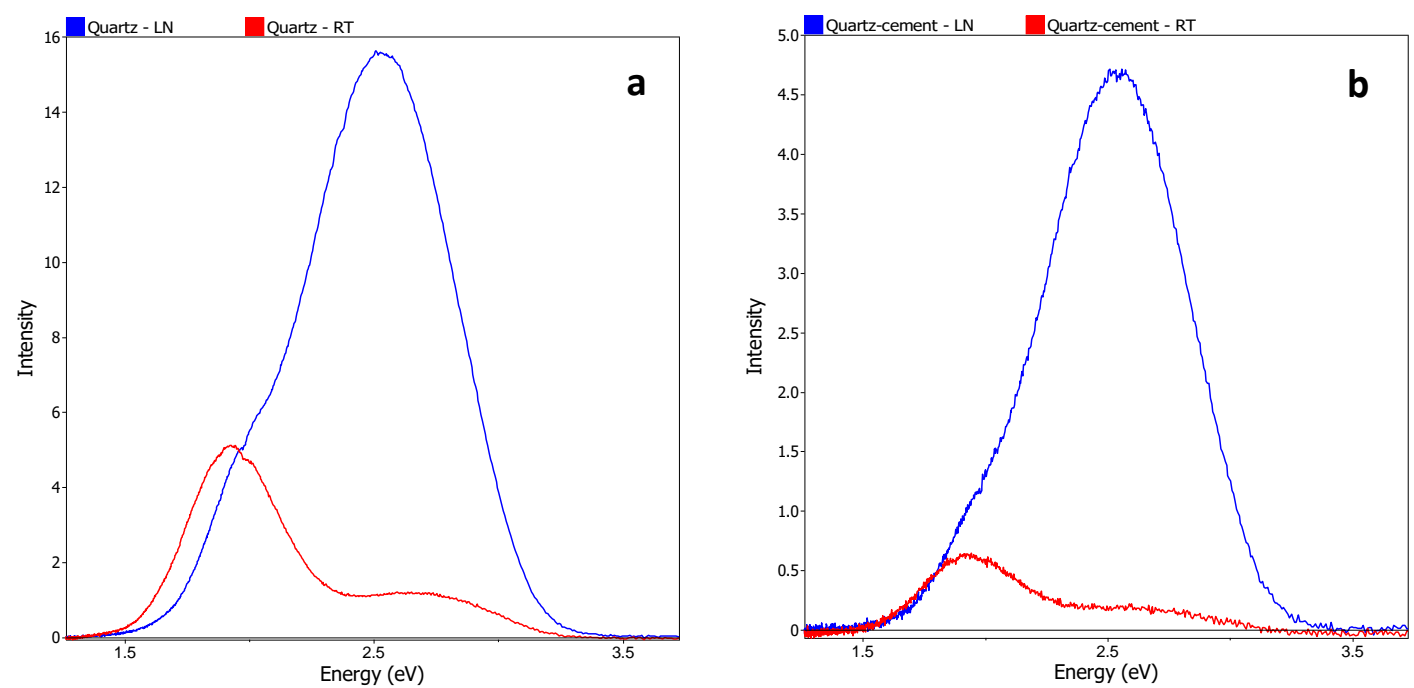

Figure 1. Spectra from Harvey 3 comparing the cathodoluminescence intensity at $296 \mathrm{~K}$ and $77 \mathrm{~K}$. a) Quartz and b) Quartz-cement. In both cases the $77 \mathrm{~K}$ cathodoluminescence emission is significantly stronger compared to at $296 \mathrm{~K}$.
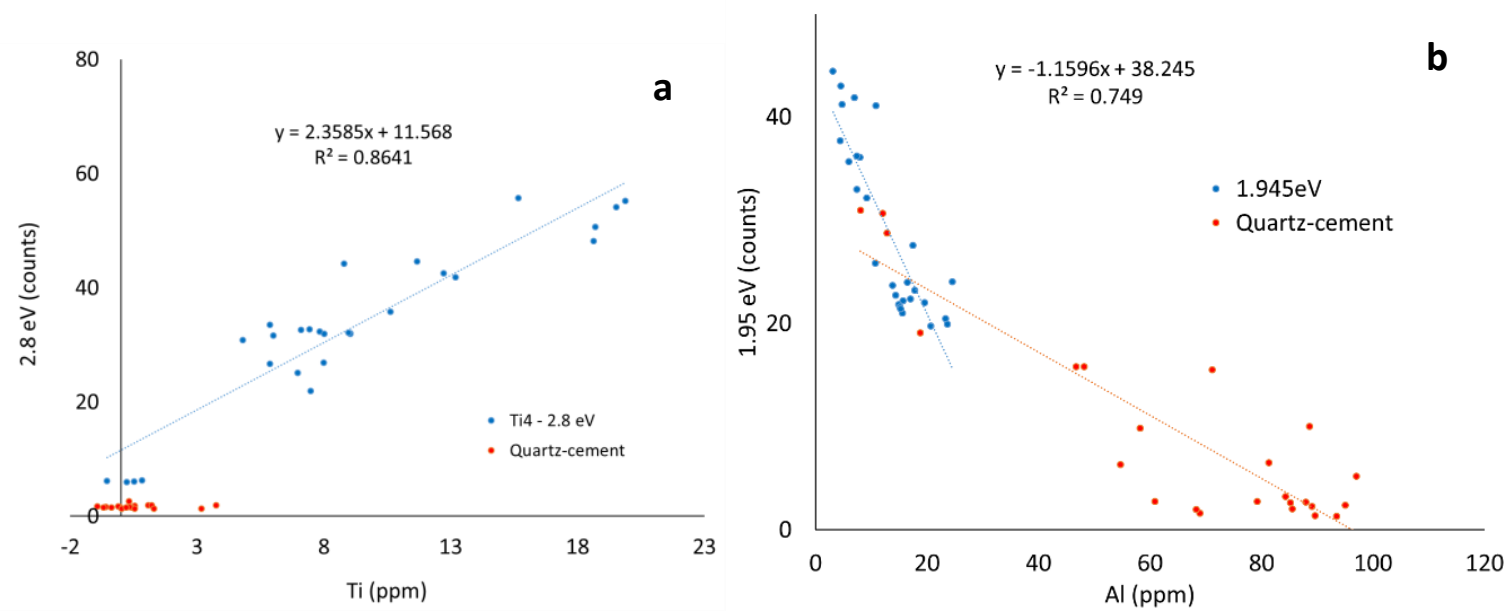

Figure 2. Quantitative elemental microanalysis of Ti compared to the extracted emission centres. a) $\mathrm{Ti}^{4+}$ emission centre, $2.8 \mathrm{eV}$ versus $\mathrm{Ti}$ shows a correlation in quartz with $\mathrm{R}^{2}$ of 0.8641 . No correlation is evident in quartz-cement, b) Al elemental concentration shows a negative correlation with the Al emssion centre, $1.945 \mathrm{eV}$, in quartz and to a lesser extent quartz-cement although with a different slope. 